\title{
Accounting Framework Based Electricity Energy Planning Software Involving Renewable Energy
}

\author{
Yusak Tanoto \\ Electrical Engineering Department \\ Petra Christian University \\ Surabaya 60236, Indonesia \\ e-mail: tanyusak@petra.ac.id
}

\author{
Ekadewi A. Handoyo \\ Mechanical Engineering Department \\ Petra Christian University \\ Surabaya 60236, Indonesia \\ e-mail: ekadewi@petra.ac.id
}

\author{
Raymond Sutjiadi \\ Computer Engineering Department \\ Institut Informatika Indonesia \\ Surabaya 60189, Indonesia \\ e-mail: raymond@ikado.ac.id
}

\begin{abstract}
This paper presents design and development of an accounting based long-term electricity energy planning software. The developed software is intended to be utilized as a learning and research tool. The software's ability includes accounting based calculation and graphical visualization of inputted values of electricity consumption and power generation capacities for baseline year. Electricity consumption growth rate projection for each supply-demand scenario is also provided to allow user work with up to five different supply-demand scenarios. Selection of fossil fuel as well as renewable energy based power plants along with several parameters settings, transmission and distribution losses calculation, resources analysis, and environmental impact calculation in terms of $\mathrm{CO}_{2}$ emission are also in the feature. The software has been well tested and results are compared to that achieved by similar other licensed software.
\end{abstract}

Keywords-electricity energy; planning; supply-demand; renewable energy; resources

\section{INTRODUCTION}

Integrated supply-demand analysis in an energy planning study has been of interests particularly in the recent decades where variables such as sustainable demand and environment concern are among important aspect. Some software are used to study and model the relation between supply and demand within a spesific energy system boundary. In addition, supplydemand condition can be modeled using several options and mechanism, such as Demand Side Management. One of the most popular tool, which is widely used in the research activity is LEAP (Long Range Energy Alternative Planning Systems), a user friendly accounting framework based simulation tool [1]. However, taken into account the importance of introducing the study of sustainable electricity energy planning in the tertiary school until undergraduate level, a simplified and more user friendly tool will be advantageous. It is difficult to find typical softwares that is designed for educational purpose, unlike on renewable energy and other tool in optimization areas [2-4].

An educational and research software program that is developed to study electricity energy planning is reported in this paper. The objective of the program is to provide an easy to use, user friendly software where users can learn energy supply-demand on electricity energy planning in the laboratory session. The program involves various fossil fueled and renewable energy based power plants in the supply side and Demand Side Management approaches in the consumption side. Under the similar framework with that used in LEAP, in the long run, the program is expected to be more advanced so that it can be used for research activities.

This paper is organized as follows. In section 2, brief review of the framework selected for the software program are given. In section 3, the method and description of the program is presented. The simulation results of the program is presented in this paper in section 4. Finally, our work of this paper is summarized in the last section.

\section{FRAMEWORK FOR ELECTRICITY ENERGY PLANNING SOFTWARE}

\section{A. Bottom-up Energy System Models}

Bottom-up energy system model is a kind of model that is intended to analyse the condition of supply-demand along with its cost and benefit, in terms of potential savings during a certain study period. It is common to include several suppydemand scenarios to study the impacts of certain scenario towards the cost, saving potentials, resources allocated, and also environmental impact. The energy system itself may consist of supply, transformation, means of delivery, and demand section. There are four major classifications of the bottom-up energy models with their distinct advantages and disadvantages. They are optimization models, iterative equilibrium/simulation models, hybrid models, and accounting frameworks. One famous tool correspond to accounting framework based model is LEAP. It is an integrated annual time step model to simulate the flow of energy from resources to utilization within a particular economic boundary. Using LEAP, several scenarios can be simulated thus analyzed in order to examine potential impacts from certain supply-demand scenarios. Example of recent research publications using LEAP can be found in the study of Estonian energy policy [5].

\section{B. Accounting Framework for the Software}

The electricity planning software is developed based on the accounting framework. The framework is calculating outcomes of decision for each supply-demand scenario. Hence, the flow 
of energy in a system is taken into account based on simple engineering relationship. Other advantages of such framework are its simplicity, flexibility, and minimum type of data requirement, that enabling the framework to examine potential impacts resulted from the scenario selection. Due to its approach, the tool based on accounting framework is not consider the least cost optimization. The basic structure applied for the software is adopted from the LEAP structure. The demand analysis, transformation, resources, and environmental analysis are taken into account.

\section{METHOdOLOGY AND DESCRIPTION OF THE SOFTWARE}

The software is built using Microsoft Visual Basic .NET 2013 and designed for running perfectly on Microsoft Windows operating system based machine (recommended Microsoft Windows 7 or above) with minimum monitor resolution 1280 x 720 pixels. Machine also needs to install .NET Framework 4.5 for running this software application. In general, there are five main features or modules in this software, to allow five analyses. All parameters that user input in this software can be saved into XML file format. With this XML file format, user can load their work before, modify, monitor the result and then save it again for future reference, without need to connect to the centralized database system via the internet. This XML file may also distributed via email or any media to other users and load it in another machine that installed the same software. Snippet of XML format used in this software is in Figure 1.

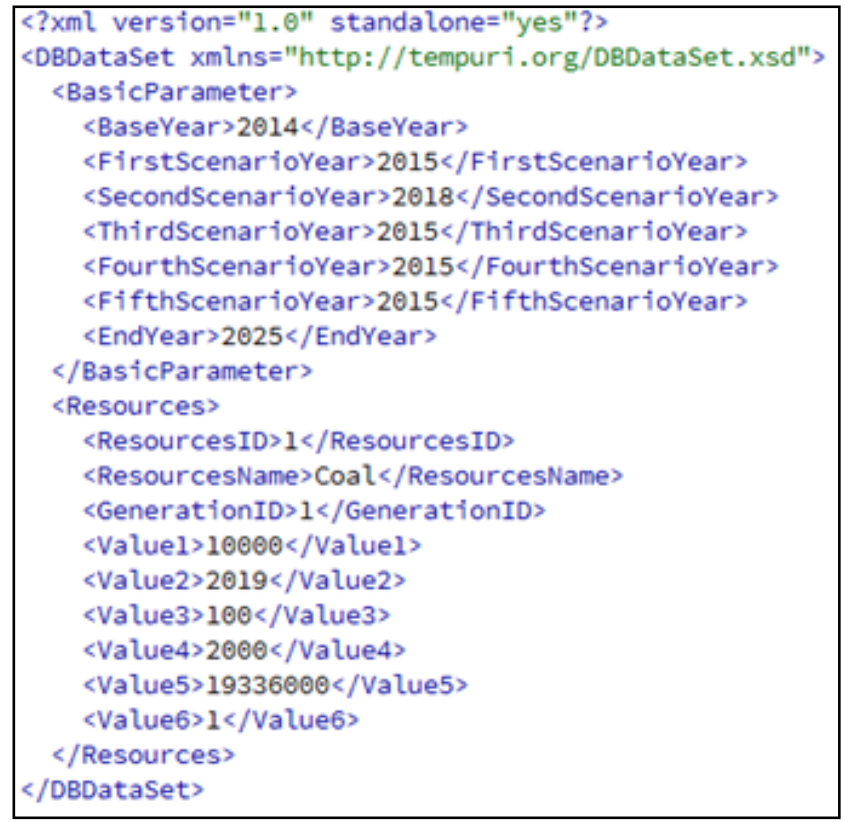

Fig. 1. XML format of the software.

Demand Basic Parameter to specify the year and scenarios is shown in Figure 2 whereas Generation Parameter setting appearance is shown in Figure 3. Similar to the setting for demand as seen in Figure 2, the software also provides year and scenario setting for generation. In addition, Demand
Parameter setting to accomodate sectors to be included in the analysis is shown in Figure 4.

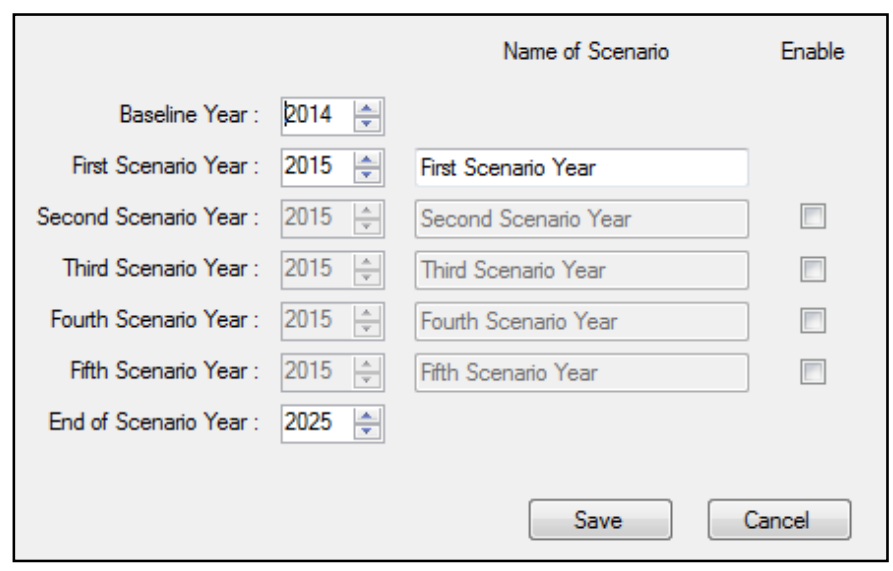

Fig. 2. Demand Basic Parameter setting caption.

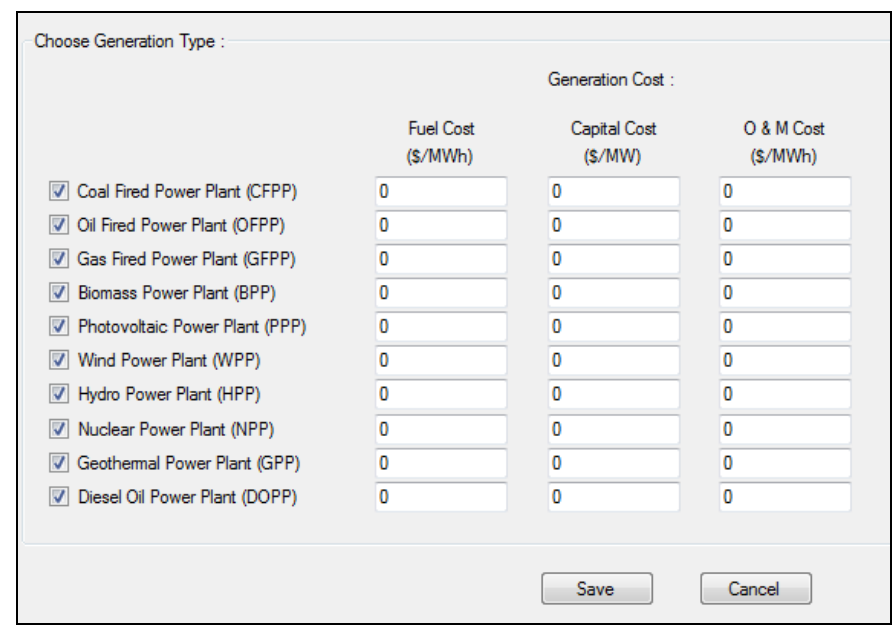

Fig. 3. Generation Parameter setting caption.

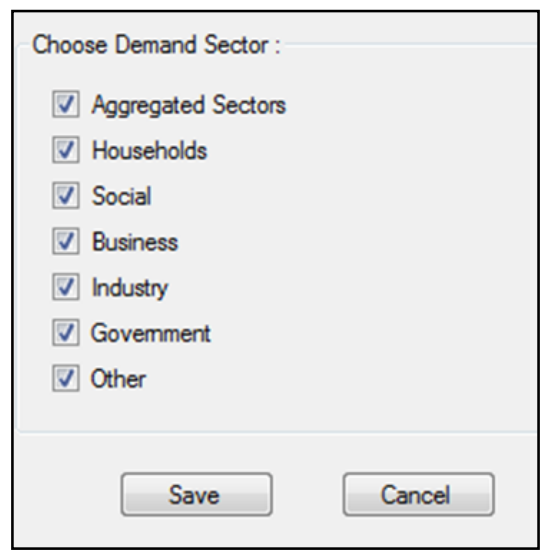

Fig. 4. Demand Parameter setting caption.

Pseudo code to make calculation among total demand, generation capacity and amount of resource, is shown in Figure 5 below: 


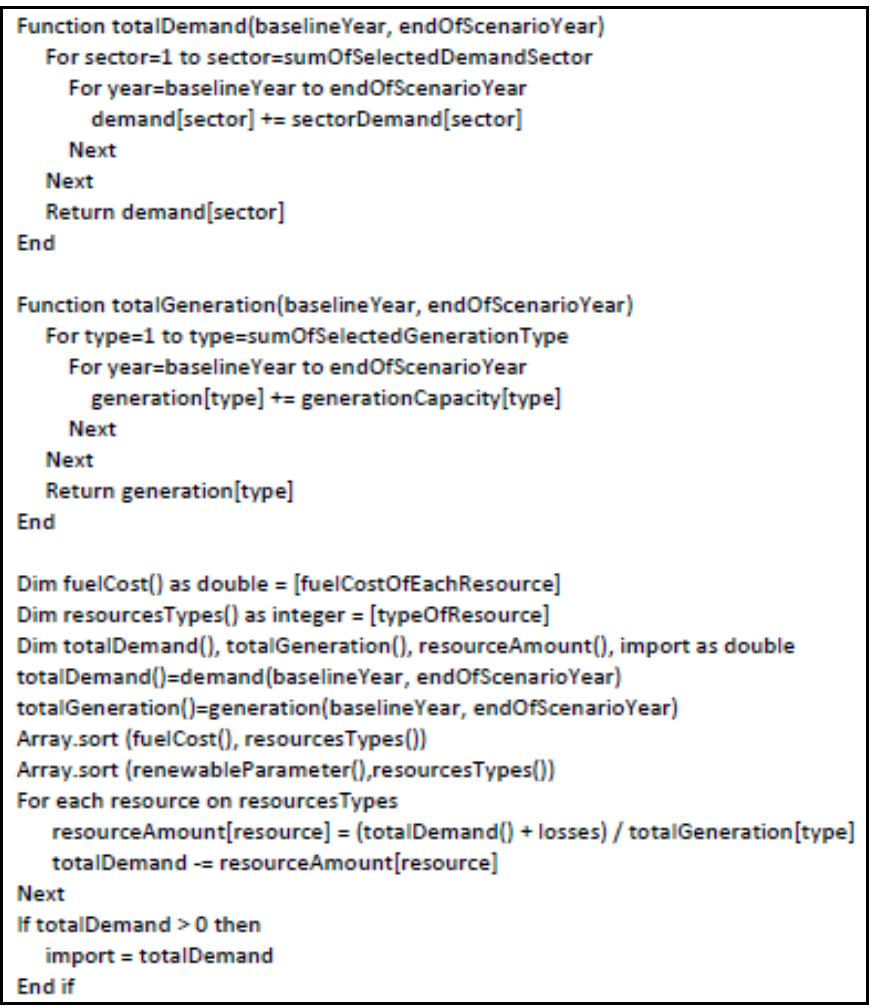

Fig. 5. The pseudo code of the software.

Each analysis module will be briefly described in the following sub sections.

\section{A. Demand Analysis}

Demand analysis calculates the growth of energy demand from baseline year until the end of scenario year, seen from many customer sectors. In the software, users can enter number of customer and total yearly energy consumption, in that particular sector. There are five customer sectors available in the software, i.e households, social, business, industry, and government. Users can also work with aggregated sectors, in the case data for each sector is not available or if the purpose of the analysis is to capture the overall total energy consumption without having to know the number of customer.

In this analysis, users are allowed to enter electricity consumption growth for each sector start from each defined scenario year. The value of growth is in percentage and may be different for each scenario year. From this analysis, users can observe which sector that encounter largest energy consumption over the study period and customers growth rate in the next few years of projection.

\section{B. Generation Analysis}

In generation analysis, users can enter selected generation capacity in MW based on the selected power plant types. Up to ten power plants technologies include coal fired, oil fired, gas fired, biomass, Photovaltaic, wind turbine, hydro, nuclear, geothermal and diesel oil power plant can be selected into analysis. Users can specify the baseline and each year capacity until the last year according to the predetermined scenario year or until the life time of the plants. Users also have to specify availability of the power plant in terms of percentage, and the dispacth order of the selected power plants.

The generation analysis calculates total yearly energy supplied and total energy losses, both in MWh. Total energy losses for each year during the study period is obtained from the power losses calculated in the transmission analysis. An option to import the electricity is also taken into account in the generation analysis, to enable system meet the demand side. This condition may be possible due to the resource depletion. From this analysis, users can see the reserve of energy that owned by a country in next few years of prediction. Each analysis feature will be briefly described in the following sub sections.

\section{Transmission and Distribution Analysis}

This analysis calculates the total losses of energy supplied on transmission and distribution lines from baseline year until end of scenario year. This percentage of losses affect to the amount of electricity energy that is distributed to the end customers. Output of delivered electricity energy from power plant equal with total of electricity energy losses added by total of electricity energy demand.

\section{Resources Analysis}

Resources analysis calculates the amount of resources that is used to supply fossil fueled based power plants to generate the electricity energy. User can specify initial reserve as the baseline reserve and make additional reserve in a certain year during the study period. Price of the reserve such as coal or oil can be entered together with the fuel heat content. The resources modul then calculates yearly reserve and consumption as well as requirement to be used by the generation. In the case resources are not sufficient, then the software will suggest an "import" option to cover the deficit whenever the deficit appeared during the study period.

\section{E. Environment Analysis}

This module quantify the impact of energy generation towards the amount of carbon dioxide emission from the selected power plants and the total amount of the emission from the system during the study period. Users can observe the amount of emission over the different scenarios.

\section{Simulation RESUlTS AND DisCUSSION}

The software is able to calculate either single scenario or multiple scenarios in one calculation. During a period of study, up to five scenarios can be applied into the model. If multiscenarios is applied, the calculation is performed progressively. For instance, a model can be developed with a "Scenario A" from year 2015 to year 2020, and continued with "Scenario B" that is applied from year 2021 to year 2025 , and followed by "Scenario C" from year 2026 to year 2027.

For the purpose of simulation, a simple case use to illustrate the utilization of the software is presented in this paper. The electricity demand data is taken from one of Regency in East Java province, Indonesia whereas the projected growth both in customer and demand is considered five years average growth. 
The simulation is caried out from the baseline year 2014 with the first scenario year on 2015 until 2025 as the last year of study. Four consumer sectors are taken into account, i.e. households, social, business, and industry. Only one scenario is applied into the model. In addition, both fossil fuel based power plants as well as renewable energy based power plants are used in the system. A region with sectoral electricity demand characteristics is shown in Table 1.

TABLE I

A REGION'S CHARACTERISTIC OF ELECTRICITY ENERGY CONSUMPTION FOR SimUlation PuRPose

\begin{tabular}{|l|c|c|c|c|}
\hline $\begin{array}{c}\text { Customer } \\
\text { Sector }\end{array}$ & $\begin{array}{c}\text { Number } \\
\text { of } \\
\text { Customer } \\
\text { in 2014 }\end{array}$ & $\begin{array}{c}\text { Number of } \\
\text { Customer } \\
\text { Growth } \\
\text { Rate (\%) }\end{array}$ & $\begin{array}{c}\text { Electricity } \\
\text { Consumption } \\
\text { (MWh) in } \\
2014\end{array}$ & $\begin{array}{c}\text { Electricity } \\
\text { Consumptio } \\
\text { n Growth } \\
\text { Rate (\%) }\end{array}$ \\
\hline Households & 284,506 & 8 & 253,968 & 8 \\
\hline Social & 9,096 & 10 & 16,378 & 8 \\
\hline Business & 7,875 & 7 & 35,337 & 10 \\
\hline Industry & 356 & 7 & 102,765 & 10 \\
\hline
\end{tabular}

In the generation sector, coal fired power plant (CFPP), photovoltaic (PPP), and geothermal power plant (GPP) are taken into account to meet the electricity consumption during the simulation period. Power plant heat rate for CFPP is set $10,498 \mathrm{Btu} / \mathrm{kWh}$. The size of CFPP is set $90 \mathrm{MW}$ along with appropriated coal resources.

In the first simulation, the regency electricity demand is satisfied initially only with CFPP until the end of the simulation period. In the second case, the demand would be meet by the three power plants. In year 2020, the PPP is added into the system with installed capacity of $10 \mathrm{MW}$, and the GPP is later on join the system in 2021 with installed capacity of 35 MW. All capacity have $95 \%$ availability. Figure 5 gives the picture of the system energy consumption involving four sectors, during year 2014 as the baseline condition until year 2025 .

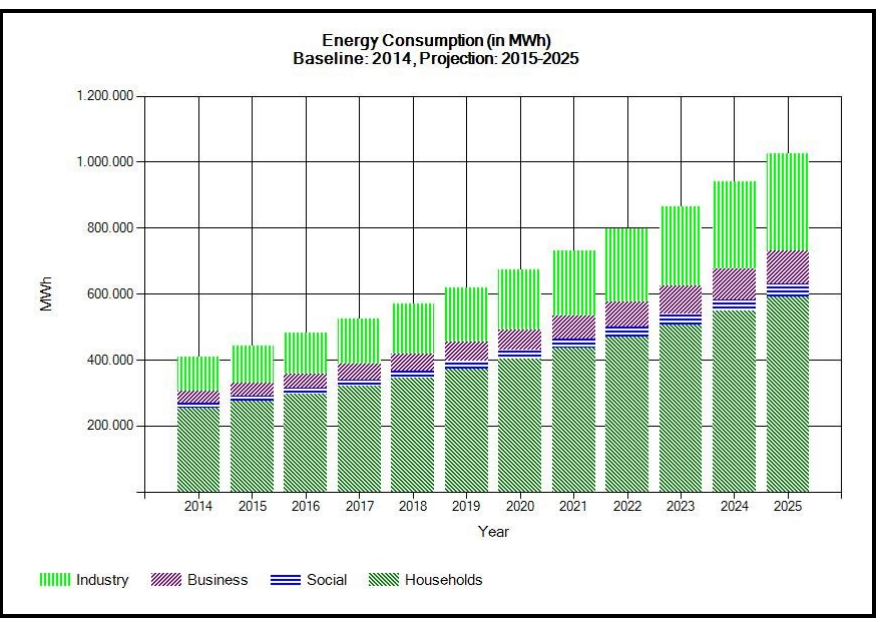

Fig. 5. Yearly energy consumption (baseline year 2014, projection year 20152025)
The power generation costs are consisting plant capital cost, fuel cost, and operation and maintenance cost. For CFPP, the costs are USD 1.126 Million per MW, USD 42.73 per MWh, and USD 6 per MWh, respectively. For PPP, the costs are USD 2 Million per MW and USD 30 per MWh with no fuel cost. Meanwhile, the costs for GPP are USD 1.8 Million per MW, USD 65.66 per MWh, and USD 10 per MWh.

In this simulation, a $10 \%$ system losses is determined for the baseline year and decreasing to only $6 \%$ in the final year. Total yearly energy supplied, in MWh, for the case of CFPP alone is obtained as seen in Figure 6 whereas for the case of all plants is shown in Figure 7. In addition, total energy losses due to transmission and distribution loss is shown in Figure 8.

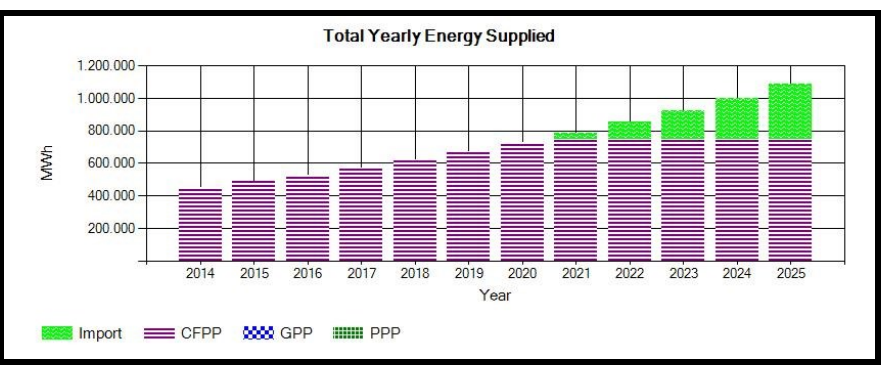

Fig. 6. Total energy supplied using CFPP only during 2014-2025 with energy import requirement.

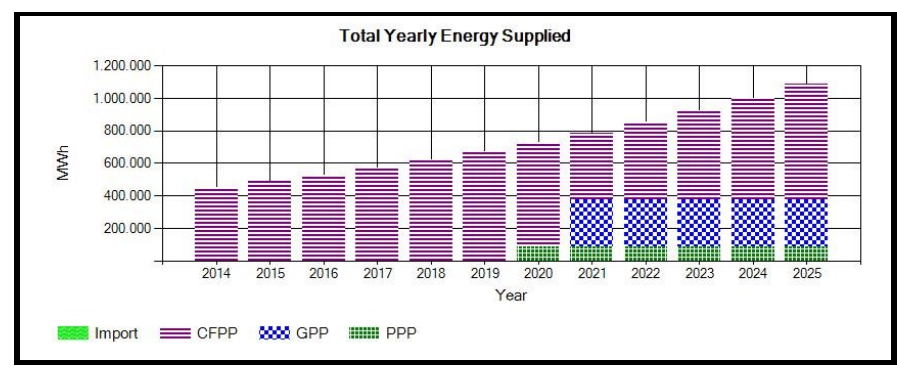

Fig. 7. Total energy supplied using CFPP only during 2014-2025 with no energy import requirement.

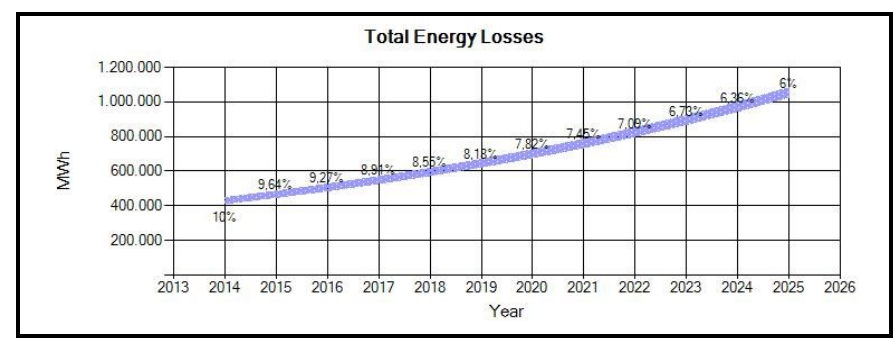

Fig. 8. Total energy losses (in MWh)

As seen in Figure 6, the energy import is required started in year 2021. In the other hand, there would be no energy import requirement if all plants are participating to meet the projected demand during 2015 to 2025 .

Total yearly energy supplied and import requirement in the case of CFPP only is shown in Table 2, whereas Table 3 shows energy supplied from all power plants. 
TABLE II

YeARLY ENERGy SUPPLIED AND IMPORTED FOR THE CASE OF CFPP ONLY (MWh)

\begin{tabular}{|c|c|c|}
\hline Year & CFPP & Import \\
\hline 2014 & 449,293 & 0 \\
\hline 2015 & 486,660 & 0 \\
\hline 2016 & 527,170 & 0 \\
\hline 2017 & 571,089 & 0 \\
\hline 2018 & 618,707 & 0 \\
\hline 2019 & 670,340 & 0 \\
\hline 2020 & 726,329 & 0 \\
\hline 2021 & 748,980 & 38,068 \\
\hline 2022 & 748,980 & 103,919 \\
\hline 2023 & 748,980 & 175,342 \\
\hline 2024 & 748,980 & 252,814 \\
\hline 2025 & 748,980 & 336,853 \\
\hline Total & $7,794,487$ & $906,996.4$ \\
\hline
\end{tabular}

TABLE III

Yearly Energy Supplied for The Case of All Plants (MWh)

\begin{tabular}{|c|c|c|c|c|}
\hline Year & CFPP & PPP & GPP & Import \\
\hline 2014 & $449,292.8$ & N/A & N/A & 0 \\
\hline 2015 & $286,660.3$ & N/A & N/A & 0 \\
\hline 2016 & $527,169.9$ & N/A & N/A & 0 \\
\hline 2017 & $571,088.6$ & N/A & N/A & 0 \\
\hline 2018 & $618,706.8$ & N/A & N/A & 0 \\
\hline 2019 & $670,339.6$ & N/A & N/A & 0 \\
\hline 2020 & $643,109.3$ & 83,220 & N/A & 0 \\
\hline 2021 & $412,557.9$ & 83,220 & 291,270 & 0 \\
\hline 2022 & $478,409.3$ & 83,220 & 291,270 & 0 \\
\hline 2023 & $549,832.4$ & 83,220 & 291,270 & 0 \\
\hline 2024 & $627,304.2$ & 83,220 & 291,270 & 0 \\
\hline 2025 & $711,342.6$ & 83,220 & 291,270 & 0 \\
\hline Total & $6,745,813.7$ & 499,320 & $1,456,350$ & 0 \\
\hline
\end{tabular}

From Figure 6, we can see that the CFPP provide sufficient supply only until year 2020. Then after, the supply is unable to meet the energy consumed until the end of the projected year, given the amount of energy losses occured during the transmission stage. In this regard, the system should import the electricity from other system. In year 2020, when additional plants entering the system, overall supply would satisfy the demand up to year 2025. Based on the simulation results, the all participating plants in the second case would provide comparative advantages over the first case. Preserving the capacity of CFPP, the potential saving of CFPP energy supplied would be around 1 Million MWh by selecting the second case configuration. The coal resource and consumption, therefore would certainly be reduced. The total generation cost for the CFPP case is around USD 613.15 Million, whereas for the case of all plants would be around USD 841 Million, taken into account $10 \%$ interest rate and $5 \%$ inflation rate.

In this simulation, users have the decision to manage the dispatch order of the power plants, following the rule determined in the analysis. The power plants can serve the base load, intermediate load, or the peak load. By having such power plants configuration, we can further analyse which one is more cost effective, whether to add some more capacity of fossil fuel or by adding more on renewables, given certain constraints. For further improvement of the software, the energy surplus analysis and avoided power plant capacity should be necessarily taken into account.

\section{CONCLUSION}

This paper reports the development and testing of an accounting based electricity energy planning model. The model is designed to simulate long term energy planning with its capability to include renewable energy resources contribution. The mechanism is simple and that is why some improvement is needed. For instance, calculation involving macro economy data to predict the consumption growth. In the future, some improvement of the software are still needed in terms of the calculation modules and the easiness of observing the analysis result in numerical as well as in the graphical presentation. In addition, capability improvement of the software to handle scenarios comparison within the same case study file and optimization of the power plants configuration will be of interests.

\section{ACKNOWLEDGEMENT}

The authors are thankfull to the grant provided by Directorate General of Higher Education (DIKTI) Ministry of Research and Higher Education of The Republic of Indonesia under Decentralization Research Scheme Grant year 2015.

\section{REFERENCES}

[1] Information on: http://www.energycommunity.org/default.asp?action=45.

[2] N. Rutten, W.R. van Joolingen, J.T. van der Veen, "The Learning Effects of Computer Simulations in Science Education," Computers \& Education, vol 58 issue 1, pp. 136-153, January 2012.

[3] P. Axaopoulos, G. Pitsilis, "Energy Software Programs for Educational Use," Renewable Energy, vol 32 issue 6, pp. 1045-1058, May 2007.

[4] "A Software Tool For Teaching of Particle Swarm Optimization Fundamentals," Advances in engineering Software, vol 39 issue 11, pp. 877-887, November 2008.

[5] P. Kuldna, K. Peterson, R.K. Thalfeldt, "Knowledge brokering on emissions modelling in strategic environmental assessment of Estonian energy policy with special reference to the LEAP model," Environmental Impact Assessment Review, vol. 54, pp. 55-60, September 2015. 